\title{
Correspondence
}

\section{Total plasma concentrations of bupivacaine, levobupivacaine and ropivacaine after combined psoas compartment-sciatic nerve block}

Marcel A. de Leeuw ${ }^{a, b}$, Pierre M. Bet ${ }^{c}$, Abraham J. Wilhelm $^{c}$, Rene M. Vos ${ }^{c}$, Martijn Hoeksema ${ }^{a, b}$, Jaap J. de Lange ${ }^{a}$, Wouter W.A. Zuurmond ${ }^{a}$ and Roberto S.G.M. Perez ${ }^{a}$

${ }^{a}$ Department of Anesthesiology, VU University Medical Center, Amsterdam, bDepartment of Anesthesiology, Zaans Medical Center Zaandam, Zaandam and 'Department of Clinical Pharmacology and Pharmacy, VU University Medical Center, Amsterdam, The Netherlands

Correspondence to Marcel A. de Leeuw, MD, Department of Anesthesiology, Zaans Medical Center, Koningin Julianaplein 58, 1500 EE Zaandam, The Netherlands

Tel: +31 756507424; fax: +31 756501929; e-mail: madeleeuw@quicknet.nl

Received 2 July 2009 Accepted 7 July 2009

Editor,

To achieve extended anaesthesia and analgesia, a psoas compartment-sciatic nerve block (PCSNB) requires administration of large volumes of potentially cardiotoxic local anaesthetics. Due to the anatomic location of the lumbar plexus [1], mostly within muscle tissue, initial absorption of the administered local anaesthetics after a psoas compartment block could result in relatively high early plasma concentrations. This phenomenon theoretically enhances the risk of local anaesthetic toxicity of this anaesthetic technique.

The primary aim of this study was to analyse total plasma concentrations after administration of the maximum recommended doses of bupivacaine, levobupivacaine and ropivacaine in a PCSNB and to compare these data with described 'threshold plasma concentration values' producing local anaesthetic toxicity. The second aim was to require more insight into pharmacokinetic profiles of used local anaesthetic administered in a PCSNB. Both aims should lead to a better understanding of the safety assessment of a PCSNB.

The present study was approved by the Medical Ethics Review Committee of the VU University Medical Centre. Patients participating in a randomized controlled trial [2], comparing the clinical efficacy of PCSNB using levobupivacaine, ropivacaine and bupivacaine, with ASA status I-III, age above 18 and scheduled for total hip replacement under general anaesthesia, were included in this study. Exclusion criteria were patients' refusal, coagulation disorders, infections at the puncture site, known allergy to local anaesthetics and preexisting neurological disorders. Patient information was given at the preoperative screening clinic and written informed consent was obtained one day prior to surgery.

Patients were randomly allocated to receive a combined PCSNB with one of three local anaesthetics: $50 \mathrm{ml}$ bupivacaine $0.3 \%$ (group BUPI), $50 \mathrm{ml}$ levobupivacaine $0.3 \%$ (group LEVO) or $50 \mathrm{ml}$ ropivacaine $0.45 \%$ (group ROPI), which are maximal recommended doses (manufacturer's indication) for a single injection peripheral nerve blockade (PNB). Patients were assigned to the treatment modalities using a block-wise randomization procedure in blocks of three. Epinephrine $1: 200.000\left(5 \mu \mathrm{g} \mathrm{ml}^{-1}\right)$ was added to all solutions. After induction of general anaesthesia, PCSNB was performed according to the landmarks described by Labat [3] and Chayen et al. [4], with the aid of a nerve stimulator and special coated, short-beveled, stimulating needles (Stimuplex HNS 11, needle $150 \mathrm{~mm} / 20 \mathrm{G}$, Braun Medical, Melsungen, Germany). Ten millilitre of local anaesthetic solution was administered to the sciatic nerve and $40 \mathrm{ml}$ was injected incrementally with gentle aspiration into the psoas compartment. The time at which all of the local anaesthetic solution had been injected was taken as time zero. Arterial plasma samples for local anaesthetic total plasma concentration analysis were taken (via radial artery catheter) before block (reference) and at 2, 5, 10, 30, 60, 90, 120, 180 and 240 min after PCSNB. Serum concentrations of bupivacaine, levobupivacaine and ropivacaine were determined by high-performance liquid chromatography with ultraviolet detection (HPLC-UV) after liquid-liquid extraction. $C_{\max }$ (maximum plasma concentration), $T_{\max }$ (time to reach $C_{\max }$ ) and area under the curve (AUC, total absorption of local anaesthetics) were determined. The AUC was calculated for $T_{0-240}$ min using the trapezium rule. Based on standard power calculation of the clinical efficacy study [2], 15 patients were needed per group. Differences between different local anaesthetics with respect to pharmacokinetic indices were analysed using the Kruskal-Wallis and the Mann-Whitney $U$-tests. Relationships between $C_{\max }$ and age, length, weight and BMI of the patient were assessed by the Spearman's $\rho$ correlation coefficient, and the Mann-Whitney $U$-test was used to assess sex-related differences in $C_{\max }$. For all analyses, an $\alpha$ value less than 0.05 was considered statistically significant.

Forty-five patients were included in the study, equally divided over the three intervention groups. All patients completed the trial. There were no differences between groups concerning patients' characteristics ('Table 1). PCSNBs were all technically successful and time between sciatic nerve and psoas compartment blocks 
Table 1 Patients' characteristics

\begin{tabular}{|c|c|c|c|}
\hline Groups & BUPI $(n=15)$ & LEVO $(n=15)$ & $\mathrm{ROPI}(n=15)$ \\
\hline Age $\left(\right.$ years) ${ }^{\mathrm{a}}$ & $69.4(12.8)$ & $60.6(16.7)$ & $69.1(10.7)$ \\
\hline Height $(\mathrm{cm})^{\mathrm{a}}$ & $167.7(8.5)$ & $167.8(9.7)$ & $163.2(10.3)$ \\
\hline Weight $(\mathrm{kg})^{\mathrm{a}}$ & $72.8(14.1)$ & $71.4(15.5)$ & $71.5(14.5)$ \\
\hline Male/Female & $3 / 12$ & $4 / 11$ & $3 / 12$ \\
\hline Duration of surgery $(\min )^{a}$ & $96(21.9)$ & $102(21.6)$ & $94(20.2)$ \\
\hline
\end{tabular}

BUPI, bupivacaine; LEVO, levobupivacaine; ROPI, ropivacaine. ${ }^{a}$ Data in means (SD).

was less than $7 \mathrm{~min}$. Total plasma concentration data of one patient within the bupivacaine group were excluded because there was an unexplained, pharmacologically impossible variation in different plasma concentration values measured at different time frames $\left(t=0\right.$ min: $0.0 \mu \mathrm{g} \mathrm{ml}^{-1}, t=2 \mathrm{~min}: 12.5 \mu \mathrm{g} \mathrm{ml}^{-1}, t=5 \mathrm{~min}:$ min: $0.26 \mu \mathrm{g} \mathrm{ml}$ ). There was no correlation between $C_{\max }$ values and sex, age, length, bodyweight and BMI.

Total plasma concentrations of ropivacaine $\left(C_{\max }\right)$ were higher than bupivacine and significantly higher than levobupivacaine (Mann-Whitney $U$-test; $P=0.036$ ) (Fig. 1). The variance of all plasma concentrations was large, regardless of which local anaesthetic was used. A notable observation is a second small increase in local anaesthetic total plasma concentration after $90-110 \mathrm{~min}$ postpuncture in all three groups.

Systemic absorption of ropivacaine $\left(\mathrm{AUC}_{0-240}\right)$ is significantly higher than bupivacaine or levobupivacaine (Kruskal-Wallis; $P<0.001$; see Table 2).

Figure 2 displays scatter plots of $C_{\max }$ versus $T_{\max }$. Lowest individual peak plasma concentration values were measured for levobupivacaine compared with bupivacaine and ropivacaine [NB: overall median $C_{\max }$ values (Table 2) were lowest for bupivacaine] and the $T_{\max }$ was longer for levobupivacaine compared with the other two local anaesthetics. Three patients within the ropivacaine group and one patient within the bupivacaine group showed large plasma concentrations (ropivacaine: 2.36, 2.76 and $3.06 \mu \mathrm{g} \mathrm{ml}^{-1}$; bupivacaine: $3.24 \mu \mathrm{g} \mathrm{ml}^{-1}$ ). Neither patient-related factors (age, weight, length) nor procedure-related factors (no blood aspiration prior injection or difficult procedure) were correlated with these relatively large plasma concentrations.

In this study, measured local anaesthetic total plasma concentrations after a PCSNB, with given dosages of
Fig. 1

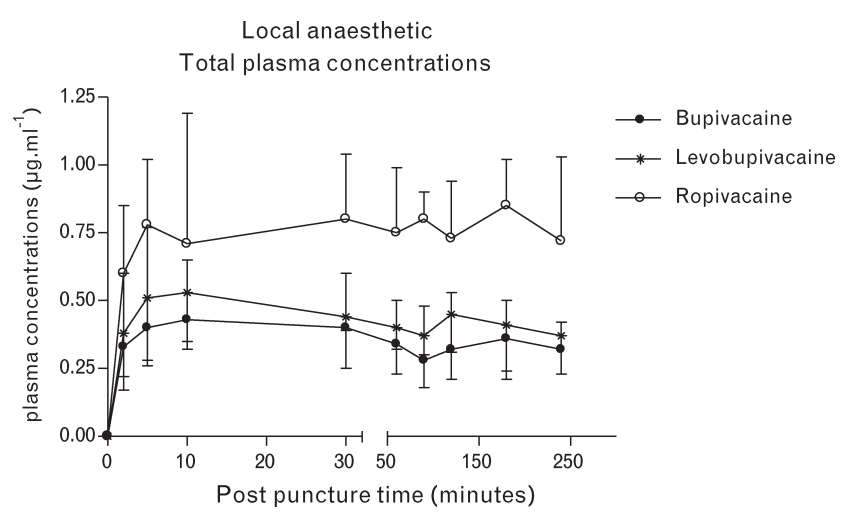

Total plasma concentrations of bupivacaine, levobupivacaine and ropivacaine after psoas compartment-sciatic nerve block. Values in median [interquartile range (IOR)].

bupivacaine, levobupivacaine or ropivacaine, remained far below described threshold values to produce central nervous system (CNS) or cardiac toxicity [5]. Probably today's dose recommendations provided by pharmaceutical companies may be conservative and the margin of safety is probably much wider than assumed.

The low local anaesthetic total plasma concentrations we found were comparable with those found in other studies concerning local anaesthetic plasma concentrations after lower extremity peripheral nerve blocks [6,7]. Recently, Vanterpool et al. [6] described a mean maximum total plasma concentration of $1.56 \mathrm{mgl}^{-1}$ ropivacaine after a PCSNB with $300 \mathrm{mg}$ ropivacaine. Higher values of their measured plasma concentrations could be explained by a higher ropivacaine dose and a lower ratio of added epinephrine.

A notable observation was a large interpatient variability in local anaesthetic plasma concentrations. This could be the result of the anatomical variation in the 'psoas compartment' [1]. Injecting local anaesthetic within highly vascularized muscle tissue could lead to higher local anaesthetic plasma concentrations than injecting local anaesthetic in a plexus sheath between different muscles. For unknown reasons, we only found high local anaesthetic plasma concentrations in one patient in the bupivacaine group and three patients in the ropivacaine group, suggesting very high initial absorption of the local

Table 2 Pharmacokinetics data

\begin{tabular}{lcrr}
\hline & Dose $(\mathrm{mg})$ & $C_{\max }\left(\mathrm{mgl}^{-1}\right)^{\mathrm{a}}$ & $T_{\max }(\mathrm{min})^{\mathrm{a}}$ \\
\hline Bupivacaine & 150 & $0.47(0.34-1.07)$ & $4.8(1.8-29.8)$ \\
Levobupivacaine & 150 & $0.64(0.46-0.90)$ & $30.2(5.2-60.0)$ \\
Ropivacaine & 225 & $0.90(0.74-1.19)$ & $5(5.0-10.0)$ \\
\hline
\end{tabular}

Reason for describing median $C_{\max }$ and $T_{\max }$ with interquartile range (IQR), instead of mean values, is the fact that given data are not normally distributed. AUC, area under the curve. ${ }^{a}$ Values are medians (IQR $\left.25-75 \%\right)$. ${ }^{b}$ Values are mean \pm SD. 
Fig. 2

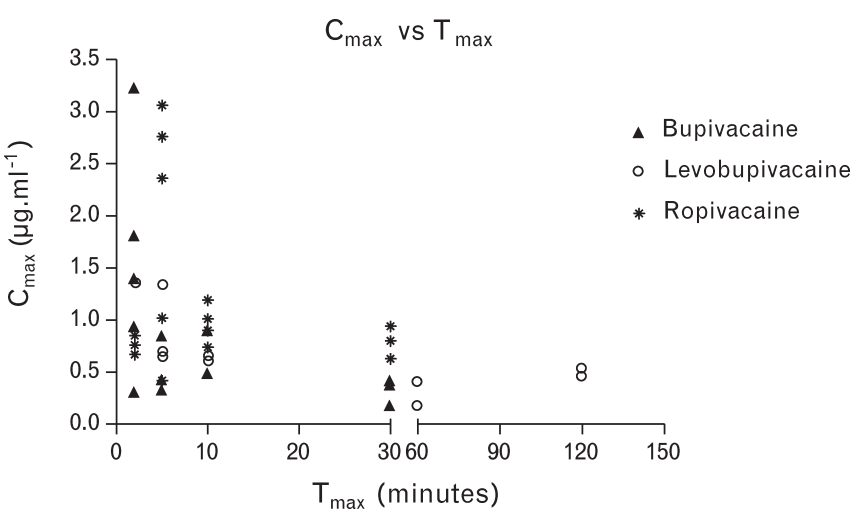

Scatter plots of maximum local anaesthetic concentration $\left(C_{\max }\right)$ by maximum time ( $\left.T_{\max }\right)$ following a single injection of $150 \mathrm{mg}$ (levo) bupivacaine or $225 \mathrm{mg}$ ropivacaine. Each symbol represents one patient. Some symbols are time-shifted by $1 \mathrm{~min}$ in order to improve readability of figure. Values in median [interquartile range (IOR)].

anaesthetics administrated in muscle tissue. Partial intravasal injection of local anaesthetics is less likely due to the absence of tachycardia and hypertension during injection (epinephrine was added as an 'intravascular marker') but could not be ruled out.

The higher maximal plasma concentration of ropivacaine compared with levobupivacaine is probably due to a higher dosage of ropivacaine (225 versus $150 \mathrm{mg}$ ).

Although the $\mathrm{AUC}_{0-240 \text { min }}$ of bupivacaine and levobupivacaine were equal, there was a trend towards levobupivacaine having a longer $T_{\max }$ compared with bupivacaine (see Fig. 2). Probably, initially systemic absorption of levobupivacaine is slower than bupivacaine and could be explained by a more vasoconstrictor effect of levobupivacaine compared with racemic bupivacaine as described by Aps and Reynolds [8]. This difference was not statistically significant and further studies are needed to analyse this phenomenon.

A notable observation was a second, small, increase in plasma concentration, within all three groups after $t=90 \mathrm{~min}$. Planned awakening at that moment from general anaesthesia, which led to a higher heart rate, blood pressure and cardiac output, resulting in a better perfusion of muscles around the psoas compartment could be the reason for this second elevation in the plasma concentrations curve. Further studies are needed to analyse the influence of cardiac output dynamics on systemic absorption of local anaesthetics.

A minor shortcoming of the present study is that only local anaesthetic total plasma concentrations were measured. The unbound local anaesthetic concentrations, which might be more closely associated with toxicity reactions, and $\alpha(1)$-acid glycoprotein were not measured. Because the unbound fraction has a similar proportional plasma concentration curve and the fact that surgery results in a rise of $\alpha(1)$-acid glycoprotein (decreasing the unbound fraction) make total local anaesthetic plasma concentration data still valuable for safety assessment.

In conclusion, total plasma concentrations of the maximum recommended doses of bupivacaine, ropivacaine and levobupivacaine used in a PCSNB remain far below the described toxicity thresholds and make the margin of safety probably much wider than current standards, allowing the usage of a higher dose than that recommended by the manufacturer. However, one should be cautious about using high doses of potentially cardiotoxic local anaesthetics in a PCSNB because the anatomic location of the lumbosacral plexus makes high initial systemic absorption possible. Finally, although not statistically significant, levobupivacaine seems to have a slower initial systemic absorption, which could make this local anaesthetic more favourable when using large dosages of local anaesthetics in a PCSNB. Further studies are needed to investigate this phenomenon.

\section{References}

1 Kirchmair L, Lirk P, Colvin J, et al. Lumbar plexus and psoas major muscle: not always as expected. Reg Anesth Pain Med 2008; 33:109-114.

2 Leeuw de MA, Dertinger JA, Hulshoff L, et al. The efficacy of levobupivacaine, ropivacaine and bupivacaine for combined psoas compartment-sciatic nerve block in patients undergoing total hip arthroplasty. Pain Pract 2008; 8:241-247.

3 Labat G. Regional anesthesia. Its technique and clinical application. Philadelphia, PA: Saunders; 1922.

4 Chayen D, Nathan $\mathrm{H}$, Chayen M. The psoas compartment block. Anesthesiology 1976; 45:95-99.

5 Bardsley H, Gristwood R, Baker H, et al. A comparison of the cardiovascular effects of levobupivacaine and rac-bupivacaine following intravenous administration to healthy volunteers. $\mathrm{Br} J$ Clin Pharmacol 1998; 46:245-249.

6 Vanterpool S, Steele SM, Nielsen KC, et al. Combined lumbar-plexus and sciatic-nerve blocks: an analysis of plasma ropivacaine concentrations. Reg Anesth Pain Med 2006; 31:417-421.

7 Kaloul I, Guay J, Côté C, et al. Ropivacaine plasma concentrations are similar during continuous lumbar plexus blockade using the anterior threein-one and the posterior psoas compartment techniques. Can J Anesth 2004; 51:52-56.

8 Aps C, Reynolds F. An intradermal study of the local anaesthetic and vascular effects of the isomers of bupivacaine. Br J Clin Pharmacol 1978; 6:63-68.

DOI:10.1097/EJA.0b013e3283308e07

\section{The use of pulse contour cardiac output-volumetric ejection fraction monitoring system in thoracic anaesthesia for high-risk patient: case report}

Tamás Végh ${ }^{\mathrm{a}}$, Krisztina Béczy ${ }^{\mathrm{a}}$, Marianna Juhász ${ }^{\mathrm{a}}$, Gábor Sira ${ }^{a}$, László Balogh ${ }^{b}$, Lukács Veres ${ }^{c}$ and Béla Fülesdi ${ }^{a}$

aDepartment of Anesthesiology and Intensive Care, University of Debrecen, Medical and Health Science Center, ${ }^{\mathrm{b}}$ Department of Cardiology and ${ }^{\mathrm{C}}$ Institute of Surgery, Center of Thoracic Surgery, Debrecen, Hungary 
Correspondence to Béla Fülesdi, MD, PhD, DSci, Department of Anesthesiology and Intensive Care, University of Debrecen, Medical and Health Science Center, Debrecen, Hungary

Tel/fax: +36 52255434; e-mail: fulesdi@dote.hu

Received 24 June 2009 Revised 2 July 2009

Accepted 7 July 2009

Editor,

During thoracic anaesthesia and in postoperative care, it is necessary to monitor haemodynamic status, especially in high-risk patients. Although the Swan-Ganz catheter is considered the gold standard advanced haemodynamic monitor, right now there is no consensus on the optimal haemodynamic monitoring method in thoracic anaesthesia for high-risk patients. We intend to present a method [the pulse contour cardiac output-volumetric ejection fraction monitoring system (PiCCO-VoLEF); Pulsion Medical Systems, Munich, Germany], which we used during thoracic anaesthesia for a patient who was to undergo heart transplantation.

A 45-year-old woman, a candidate for heart transplantation, had had previous history of hypertension, insulindependent diabetes mellitus (IDDM) and myocardial infarction and had undergone three-vessel coronary artery stenting as well as implantable cardioverter defibrillator (ICD) implantation. During her preoperative evaluation for heart transplantation, a tumour, $19 \mathrm{~mm}$ in diameter, was found in her right lung. Subsequently, a thoracoscopic partial lung resection was planned in order to verify the nature of the tumour.

\section{Perioperative assessment and preparation}

From among the preoperative evaluation results, we intend to highlight the results of echocardiography, exercise test and invasive haemodynamical measurement.

Echocardiography revealed a second to third degree mitral insufficiency and tricuspidal insufficiency, dilated left ventricle and atrium, diffuse hypokinesis and akinesis, a $60 \mathrm{mmHg}$ right ventricular systolic pressure and a $15 \%$ ejection fraction. In dobutamine stress echocardiography combined with the Swan-Ganz catheter, no viability was seen at the myocardium after stent implantation, but chronotropic incompetence and improvement in the heart function were present.

The day before surgery, a VoLEF pulmonary catheter (PV2047, VoLEF Catheter PACG 947, Pulsion Medical Systems) was inserted via the right internal jugular vein into the right pulmonary artery under the guidance of flouroscopy. Because the VoLEF pulmonary catheter has no shield, of its own, we used the standard pulmonary artery catheter shield (Catheter Contamination Shield $80 \mathrm{~cm}$, Edwards Lifesciences, Irvine, California, USA). After catheter fixation, we inserted a PiCCO catheter (PV2015L20A, Pulsiocath; Pulsion Medical Systems) into the right femoral artery and performed the baseline measurements. For haemodynamic monitoring, we used a combination of PiCCO Plus V 5.2.2 and VoLEF V 1.0 (Pulsion Medical System) monitors.

\section{Intraoperative phase}

On the morning of the surgery, we switched the ICD to pacemaker mode via telemetry.

At the time of skin incision, one-lung ventilation (OLV) was started with a $\mathrm{fiO}_{2}$ of $100 \%$. The surgical plan was originally a video-assisted thoracoscopic surgery (VATS), but due to adhesions caused by previous pneumonias, intraoperatively, an open thoracotomy was decided. At 15 min of OLV, the pulmonary vascular resistance (PVR) increased, tachycardia and then bradycardia developed, and then the $\mathrm{SatO}_{2}$, pulmonary artery pressure (PAP) and cardiac output (CO) decreased and central venous pressure (CVP) increased. We immediately started and continued double-lung ventilation until the end of surgery and the administration of dobutamine, norepinephrine and the infusion rate was increased. The above parameters were normalized in a few minutes. The remaining part of the surgery was uneventful and we were able to decrease the dose of dobutamine and norepinephrine. The surgeons performed the resection of the eighth segment of the right lung. After completion of the surgery, we changed the double-lumen tube (DLT) to a single-lumen tube and transported the patient to the ICU under sedation and mechanical ventilation.

In the ICU, we omitted norepinephrine and gradually decreased the dose of dobutamine. In the sixth postoperative hour, we could extubate the patient and switched the ICD on. On the third postoperative day, we omitted dobutamine and on the fourth day, we removed the haemodynamic catheters and the chest tubes; the patient was admitted to the ward and on the tenth postoperative day, the patient left the hospital. The results of haemodynamic monitoring during the perioperative period are shown in Fig. 1.

We were facing hard pathophysiological conditions and we chose a monitor that enabled us to meet the monitoring requirements. The underlying conditions that we had to face were as follows:

(1) Left and right heart failure and dilation, tricuspidal and mitral regurgitation, elevated right ventricular and pulmonary arterial pressure, ICD in situ: as mitral and tricuspidal regurgitation caused dilated pulmonary vessels, we found the wedge-position very peripheral $(60 \mathrm{~cm})$. Additionally, we had to avoid knotting of the long pulmonary catheter and the ICD electrode inside the heart during insertion. Fortunately, the VoLEF pulmonary catheter is radiopaque and $110 \mathrm{~cm}$ long, so under fluoroscopic guidance, the positioning of the catheter to the correct place became possible. 


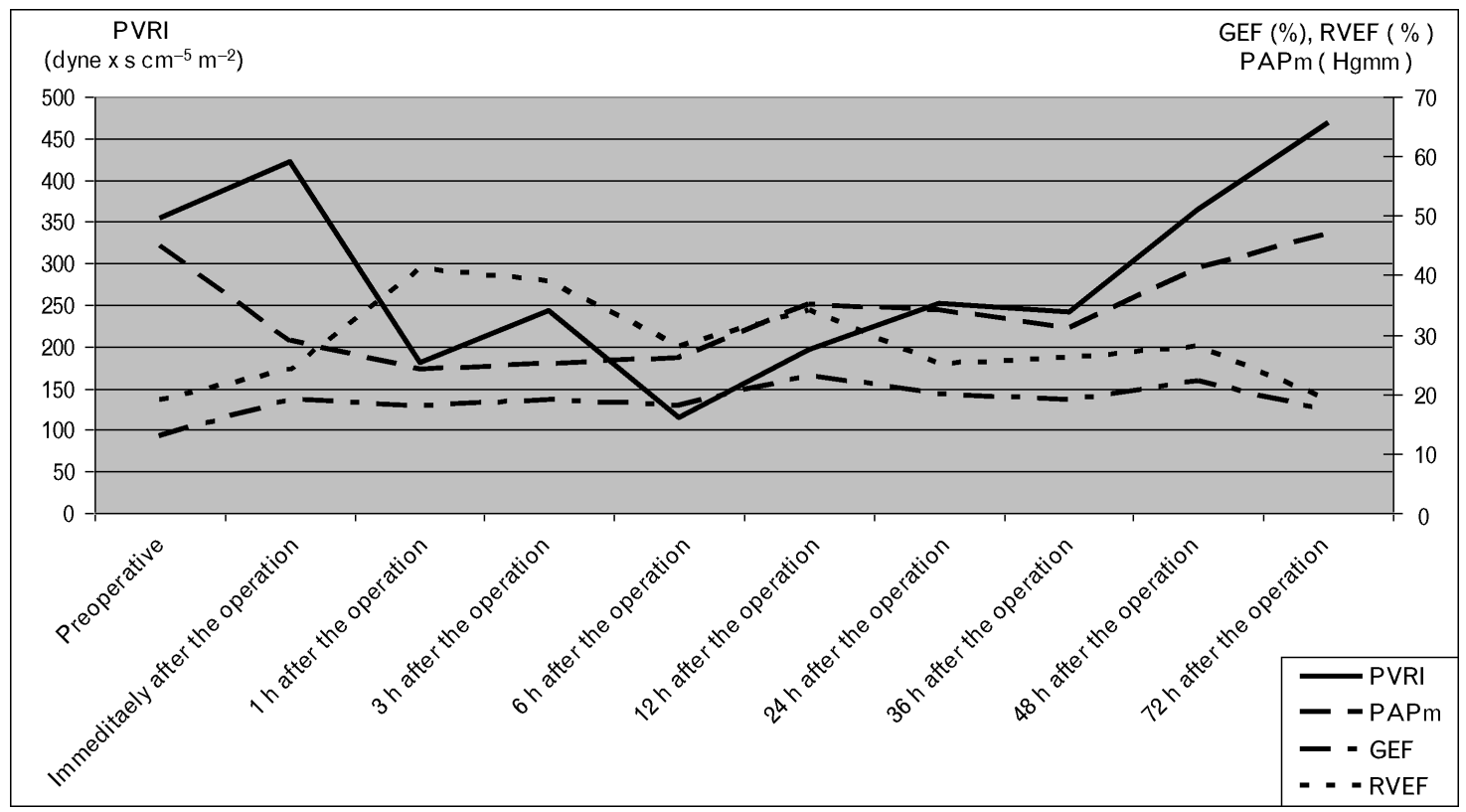

Results of haemodynamic measurements in the perioperative period. GEF, global ejection fraction; PAP, pulmonary artery pressure; PVRI, pulmonary vascular resistance index; RVEF, right ventricular ejection fraction.

(2) Hypoxic pulmonary vasoconstriction: if alveolar oxygen tension falls below $60 \mathrm{mmHg}$, hypoxic pulmonary vasoconstriction occurs. This vasoconstriction is a significant afterload for the right ventricle, especially if it is impaired. An acute elevation of the afterload causes a dilatation of the impaired right ventricle and the interventricular septum is shifted towards the left ventricle, resulting in a decrease in the diastolic filling of the left ventricle. This decreased left ventricular filling leads to a decrease in $\mathrm{CO}$ and a consequent collapse of the circulation. The PiCCO-VoLEF monitor enabled us to measure PVR, right ventricular ejection fraction (RVEF), the ratio of the right and left heart $(\mathrm{R} / \mathrm{L})$, the right heart and left heart end-diastolic volume (RHEDV, LHEDV) and PAP. With the help of this monitor, the diagnosis and the immediate treatment of the left and right heart failure became possible. One of the most important parameters of systemic circulation for us was systemic vascular resistance (SVR), because the patient had mitral insufficiency in her previous history and we had to secure optimal vascular resistance both because of the left ventricle and because of the previous mitral insufficiency. In order to decrease PAP, we used dobutamine and we compensated for its systemic vasodilatory effect with norepinephrine. Optimization of SVR increased the left ventricular filling, because it pushed the interventricular septum back towards the right ventricle. In contrast to this, an elevated SVR would increase the regurgitant blood volume to the left atrium and would decrease $\mathrm{CO}$ [1-6].

(3) Increased blood flow in the lung (fluid overload): after pulmonary resection, sometimes acute lung injury (ALI) and pulmonary oedema may occur. The origin of this oedema is complex and not entirely clear: surgical manipulation, fluid overload, damage to the alveolarcapillary barrier from mechanical ventilation and the reexpansion of the lung are all implicated. With the use of the PiCCO-VoLEF monitor, one can identify the pulmonary oedema by measuring extravascular lung water $(\mathrm{EVLW})$. The use of this monitoring technique helps to differentiate between the oedemas of different origins; if the pulmonary vascular permeability index (PVPI) is below 3, the oedema is most probably of cardiac or hydrostatic origin and if the PVPI is greater than 3, the origin of the oedema is postresectional ALI/adult respiratory distress syndrome (ARDS). The use of this monitoring technique also enables us to guide fluid therapy according to needs $[7,8]$.

During thoracic anaesthesia for high-risk patients, the anaesthesiologist has to know the pressure of the pulmonary vascular system, the left/right and global heart functions and the EVLW/PVPI. These parameters can be measured separately with pulmonary artery catheter and a PiCCO monitor, but the combined use of the PiCCOVoLEF monitor makes it possible for the anaesthesiologist to use only one system. 


\section{References}

1 Waller AD, Keavey P, Woodfine L, Dark JHI. Pulmonary endothelial permeability changes after major lung resection. Ann Thorac Surg 1996; 61:1435-1440.

2 Della Rocca G, Costa MG. Preload indexes in thoracic anesthesia. Curr Opin Anaesthesiol 2003; 16:69-73.

3 Della Rocca G, Costa MG. Hemodynamic-volumetric monitoring. Minerva Anesthesiol 2004; 70:229-232.

4 Della Rocca G, Costa GM, Coccia C, et al. Preload index: pulmonary artery occlusion pressure versus intrathoracic blood volume monitoring during lung transplantation. Anesth Analg 2002; 95:835-843.

5 Chiu CL, Mansor M, Majid A. Anaesthetic management of high-risk cardiac patients undergoing thoracic surgery with the support of intra-aortic balloon pump. Br J Anaesth 2005; 94:688-689.

6 Roch A, Michelet P, D'journo B, et al. Accuracy and limits of transpulmonary dilution methods in estimating extravascular lung water after pneumonectomy. Chest 2005; 128:927-933.

7 Monnet X, Anguel N, Osman D, et al. Assessing pulmonary permeability by transpulmonary thermodilution allows differentiation of hydrostatic pulmonary edema from ALI/ARDS. Intensive Care Med 2007; 33:448453.

8 Slinger P. Fluid management during pulmonary resection surgery. Ann Cardiac Anaesth 2002; 5:220-224.

DOI:10.1097/EJA.0b013e3283308e6b

\section{Current nitrous oxide use in general anaesthesia: an electronic survey Moses Chikungwa}

Mid Stafforshire Hospital NHS Foundation Trust, Weston Road, Stafford, ST16 3SA, UK

Correspondence to Moses Chikungwa, Mid Stafforshire Hospital, NHS Foundation Trust, Weston Road, Stafford, ST16, UK

Received 27 July 2009 Revised 7 August 2009

Accepted 10 August 2009

Editor,

At the age of 165 nitrous oxide is twice as old as the oldest practising anaesthetist! As an anaesthetic agent it has had better success at weathering critical reviews and standing the test of time than any other agent. It has been suggested that it owes this success to the fact that it is a weak anaesthetic/analgesic agent with mild adverse effects during an average time use. However, recent research suggests that there are serious adverse events that occur postoperatively due to nitrous oxide. These morbidities are either inadvertently attributed to other causes or the link to the real culprit, nitrous oxide, is nebulous and blurred. The most obvious distressing side effect, but which is not directly fatal, is postoperative nausea and vomiting (PONV). Several trials have shown a significant reduction in PONV by omitting nitrous oxide [1]. The other side effects are long-term and are either due to recreational abuse or prolonged exposure [2]. As a result there is no universality in the use of nitrous oxide as a routine anaesthetic agent, with some practitioners calling for an all out ban on its use. This survey was carried out to assess which way the pendulum is swinging regarding the use of nitrous oxide.

\section{Method}

An electronic questionnaire was sent to members of the European Society of Anaesthesiology (ESA) through the ESA Secretariat. Responding members sent their completed questionnaires directly to the author by E-mail.

\section{Results}

A total of 123 questionnaires were returned from all over the world, with the majority of the responses coming from Europe (Table 1). The majority $(86.1 \%)$ of respondents were specialist anaesthesiologists or consultants. Out of the total $64.3 \%$ admitted to using nitrous oxide in their clinical practice. Approximately $29 \%$ of the nitrous oxide users always use it for general anaesthesia without exception. The cases in which nitrous oxide is used included in-patients, day surgery and paediatric patients. The majority $(71 \%)$ of nitrous oxide users would not use it in some cases. Only $33 \%$ (41) of the total respondents never at all use nitrous oxide in their practice. Air is used by the majority $(73.2 \%)$ of anaesthesiologists as an alternative to nitrous oxide. Xenon is still not widely used (1.6\%). Of the respondents from the UK $92 \%$ use nitrous oxide compared with $50 \%$ in Holland, $50 \%$ in Spain and $30 \%$ in Germany.

On the prediction of the future use of nitrous oxide, $53 \%$ believe nitrous oxide will disappear from routine clinical use. Reasons expressed by proponents for the use and for nonuse of nitrous oxide range from clinical to environmental issues. Proponents for nitrous oxide use emphasized time-tested safety record, low cost anaesthesia and convenience. On the contrary nonusers highlighted PONV, the emerging myocardial adverse effects, and more importantly the fatalities that ensue when human error comes into play, something that would never happen with use of air. Table 2 shows commonly cited reasons for and against use of nitrous oxide.

\section{Discussion}

The survey clearly shows that nitrous oxide is still pretty much in vogue with the current generation of anaesthesiologists notwithstanding the piling evidence against it. The majority of the respondents (64.3\%) use nitrous oxide in their anaesthetic practice, with a minority (33.3\%) never at all using it. A similar survey 7 years

Table 1 Countries of practice and number of respondents

\begin{tabular}{|c|c|c|}
\hline Country and number of respondents $(N)$ & & \\
\hline Argentina 8 & Indonesia 1 & Romania 1 \\
\hline Austria 3 & Iran 1 & Russia 3 \\
\hline Australia 2 & Israel 1 & Serbia 2 \\
\hline Belgium 1 & Italy 7 & Slovakia 1 \\
\hline Bulgaria 1 & Japan 1 & Slovenia 1 \\
\hline Croatia 3 & Jordan 1 & Spain 6 \\
\hline Czech 1 & Kazakhstan 1 & Sweden 2 \\
\hline Denmark 2 & Korea $(\mathrm{N}) 1$ & Switzerland 6 \\
\hline Finland 1 & Latvia 1 & Turkey 2 \\
\hline France 4 & New Zealand 1 & UK 12 \\
\hline Germany 10 & Poland 3 & USA 3 \\
\hline Holland 8 & Portugal 1 & \\
\hline
\end{tabular}




\begin{tabular}{|c|c|}
\hline For & Against \\
\hline Analgesia (obstetric and perioperative) & $\begin{array}{l}\text { Significant side effects (PONV, myocardial depression, expansion of } \\
\text { gas filled cavities, anaemia) }\end{array}$ \\
\hline $\begin{array}{l}\text { Anaesthesia (augments, good for high risk of awareness patients, } \\
\text { spares volatile, quick onset/offset, good for paediatric cases, low cost agent) }\end{array}$ & Harm much greater than usefulness \\
\hline Traditional, acceptable practice & Unnecessary, better alternatives available \\
\hline Cheap, well tolerated, convenient & Low anaesthetic and analgesic potency \\
\hline Useful in certain procedures (retinal detachment, tympanoplasty) & Environmental pollutant and greenhouse effect \\
\hline \multirow[t]{2}{*}{ Mild side effects compared with other agents } & Possible teratogenicity (pregnant staff) \\
\hline & Mistakes may be fatal \\
\hline
\end{tabular}

ago showed that $95 \%$ of UK anaesthetists used nitrous oxide (frequently or occasionally), with a tiny minority (5\%) never using it [3]. These results, albeit from a small sample, show that in the UK there has not been any change in the usage of nitrous oxide since the Henderson et al. [3] survey in 2002. However, in Europe the drive to remove nitrous oxide from routine practice seems to be moving faster than in the UK. Some of the European respondents reported that nitrous oxide has been banned and is no longer available in their hospitals.

Biochemically nitrous oxide inhibits methionine synthase, an essential ubiquitous cytosolic enzyme, by oxidizing the cobalt ion in cobalamin (vitamin B12) from $\mathrm{Co}^{+}$to $\mathrm{Co}^{3+}$. This results in failure to generate the intermediary methyl donor, S-adenosylmethionine, key to the synthesis of DNA, RNA, myelin, catecholamines and other substances requiring the methylation process. Folate is an intermediary in the methylation process and is essential in the biosynthesis of purines, pyrimidines, serine and glycine. Homocysteine levels rise due to the blockade of methionine synthase. Homocysteine has been shown to cause endothelial dysfunction and increased tendency to coagulation. The biosynthetic dysfunction caused by nitrous oxide provides the link to the feared teratogenic, subacute combined neurodegeneration of the cord, haematological toxicity, immune dysfunction, and myocardial ischaemic complications of nitrous oxide [4].

Except in cases of abuse, the nationally set occupational exposure limits (OEL) guarantee minimal safe exposure in clinical practice. However, this does not apply to the patient whose exposure is time-dependent. Methionine synthase activity approaches zero after about $200 \mathrm{~min}$ of exposure to nitrous oxide in mice [5]. For the average clinical exposure of about $1.5 \mathrm{~h}$ there is a $50 \%$ reduction in methionine synthase activity and takes 3-4 days to fully recover. Although the ENIGMA I trial [1] demonstrated a reduction in major complications with avoidance of nitrous oxide, it has been suggested that it was probable that the use of high oxygen $(80 \%)$ was the reason rather than omission of nitrous oxide. That fact was confirmed earlier by Fleischmann et al. [4], who found no statistically significant difference in the rate of infection and other secondary outcomes between use of nitrous oxide and nitrogen. The ENIGMA I group has since embarked on ENIGMA II, which might shed more light on the clinical adverse effects, if any, of nitrous oxide, particularly the endothelial dysfunction related to perioperative high levels of homocysteine [6,7].

The use of anaesthetic machines without antihypoxia devices or some other mishap in which nitrous oxide is delivered without oxygen have resulted in fatalities. Such accidents do not occur when air is substituted for nitrous oxide. It can be argued that, except for these cases of human error, nitrous oxide has been successfully used in clinical practice without major problems for more than one and half centuries. Use of nitrous oxide more than doubles the incidence of postoperative nausea and vomiting [1]. This is the most quoted reason in the survey for abandoning use of nitrous oxide. A real threat to nitrous oxide, however, is posed by its being the third most climatologically significant greenhouse gas after carbon dioxide and methane [8]. With a 120 year long atmospheric lifetime and 300 times the global warming potential of carbon dioxide, nitrous oxide is likely to be banned from use unless ways are found to prevent atmospheric pollution. Most of the atmospheric nitrous oxide (99\%), however, originates from agricultural and industrial sources, with probably about $0.05 \%$ coming from medical and dental use. The impact of eliminating medical and dental nitrous oxide contributions on the greenhouse effect is not known, but it is thought it would be negligible.

The limitation of the survey is that it was small, and, like any survey, may suffer from response bias. However, this was an international survey and therefore probably provides a global opinion on the use of nitrous oxide.

\section{Conclusion}

Nitrous oxide occupies such a unique niche that no other agent has managed to dislodge it for more than one and half centuries. Although there is a trend towards reducing use of nitrous oxide, it is quite probable that this agent will outlive any currently practising anaesthesiologist.

\section{References}

1 Myles PS, Leslie K, Chan MTV, et al. Avoidance of nitrous oxide for patients undergoing major surgery. A randomised controlled trial. Anesthesiology 2007; 107:221-231.

2 Suruda AJ, McGlothlin JD. Fatal abuse of nitrous oxide in workplace. J Occupational Med 1990; 32:682-684. 
3 Henderson KA, Raj N, Hall JE. The use of nitrous oxide in anaesthetic practice: a questionnaire survey. Anaesthesia 2002; 57:1155-1158.

4 Fleischmann E, Lenhardt R, Kurz A, et al. Nitrous oxide and risk of surgical wound infection: a randomised trial. Lancet 2005; 366:1101-1107.

5 Koblin DD, Watson JE, Deady JE, et al. Inactivation of methionine synthetase by nitrous oxide in mice. Anesthesiology 1981; 54:324-335.

6 Badner $\mathrm{NH}$, Drader K, Freeman D, et al. The use of intraoperative nitrous oxide leads to postoperative increase in plasma homocysteine. Anesth Analg 1998; 87:711-713.

7 Badner $\mathrm{NH}$, Beattie WS, Freeman D, et al. Nitrous oxide-induced increased homocysteine concentrations are associated with increased postoperative myocardial ischaemia in patients undergoing carotid endarterectomy. Anesth Analg 2000; 91:1073-1079.

8 Dentener F, Derwent R, Dlugokencky E, et al. Atmospheric chemistry and greenhouse gases. In: Climate Change 2001: The Scientific Basis. Contribution of Working Group I to the Third Assessment Report of the Intergovernmental Panel on Climate Change. Houghton JTY, Ding DJ Griggs M, et al., editors. Cambridge: Cambridge University Press; 2001. pp. 239-288.

DOI:10.1097/EJA.0b013e328331c738

\section{Can't intubate, can't ventilate: rescue airway using a size $2^{1 / 2}$ laryngeal mask airway in a morbidly obese female patient}

\section{Suzi L. Lomax ${ }^{a}$, Robin Loveland ${ }^{\mathrm{b}}$ and Jairaj Rangasami ${ }^{\mathrm{b}}$}

aNuffield Department of Anaesthetics, John Radcliffe Hospital, Oxford and

bexham Park Hospital, Slough, UK

Correspondence to Suzi L. Lomax, BM (Hons), BSc (Hons), FRCA, Specialist Registrar in Anaesthesia, Nuffield Department of Anaesthetics, John Radcliffe Hospital, Oxford, UK

Tel: +44 01865 22159; fax: +44 01865220027 ;

e-mail: slterry@doctors.org.uk

Received 23 January 2009 Accepted 23 January 2009

\section{Editor,}

With the incidence of obesity increasing in the UK, difficult mask ventilation with increasing BMI is well documented. The laryngeal mask airway (LMA) is an established adjunct for use when difficulty is encountered with mask ventilation. We describe a case of a morbidly obese female patient which deteriorated into a can't intubate, can't ventilate (CICV) scenario and how the situation was salvaged using a paediatric-sized LMA when other recognized techniques had failed. This is the first documented case of a paediatric-sized LMA being used as a rescue technique in an adult CICV scenario.

\section{Case report}

A 51-year-old female patient, known to be a Lehane and Cormack grade 4 laryngoscopy, presented for elective revision of a left total elbow replacement. At $110 \mathrm{~kg}$, she had a BMI of 50. Apart from juvenile arthritis, her past medical history was unremarkable and she denied symptoms of obstructive sleep apnoea. Examination revealed a morbidly obese female patient with mouth opening of two fingers due to temporomandibular joint involvement and a Mallampati grade 4 view. She had a receding mandible and limited neck extension. The cricothyroid membrane was not palpable. Other examination and investigations were normal. For the original operation 2 years previously, the anaesthetist had abandoned an awake fibre-optic intubation (FOI) due to the patient being unable to tolerate it. Anaesthesia was achieved at that time using a gas induction, with mask ventilation made possible using a two-person technique. Intubation was ultimately performed fibre optically using a size 3 LMA. Extubation and the postoperative period had been uneventful. Over the intervening 2 years, the patient had gained $20 \mathrm{~kg}$. A combined regional and general anaesthesia approach was planned. However, after her previous experience, despite counselling, the patient refused to undergo an awake FOI. Therefore, the initial plan was to induce anaesthesia while maintaining spontaneous ventilation and to perform an oral FOI using a Berman airway (Vital Signs, Littlehampton, UK). The back-up plan was to wake the patient up. The patient consented, and risks including hypoxic brain injury and death were discussed. Two anaesthetists with experience in difficult airway management were present, and an ear, nose and throat (ENT) surgeon was immediately available. The patient was positioned using a 'ramping' technique and the airway topicalized using $4 \%$ lidocaine. After preoxygenation, anaesthesia was induced using increments of propofol followed by a maintenance of sevoflurane in oxygen to maintain spontaneous ventilation. Oral FOI via the Berman airway failed due to supraglottic tissue folds obstructing the view, despite repositioning and resizing of the Berman airway. During this time, the airway had become increasingly obstructed despite maximum jaw thrust and a two-person mask technique. Despite success at the previous anaesthetic, oropharyngeal, nasopharyngeal airways and a size 3 LMA failed to improve the now impending CICV situation. A size $2 \frac{1}{2}$ classic LMA was inserted in an attempt to provide better positioning in the airway with the shorter tube length and smaller mask. Immediately on insertion, there was resolution of the clinical signs of obstruction. Anaesthesia was maintained using sevoflurane, and the size $2 \frac{1}{2}$ LMA was used as a conduit for a fibre optically placed Aintree intubating catheter (AIC) (Cook, Letchworth, UK), before removal of the LMA and railroading of a size 6.5 Fastrach endotracheal tube (Intavent Orthofix, Maidenhead, UK). An axillary brachial plexus block was performed and the $2^{1 / 2} \mathrm{~h}$ operation proceeded uneventfully. Prior to extubation, the AIC was reinserted and the patient extubated in the upright position fully awake. The postoperative period prior to discharge was uncomplicated.

\section{Discussion}

This is the first case in the literature in which a size $2 \frac{1}{2}$ LMA has been used, not only as a rescue technique but also as a conduit for intubation in the difficult adult airway. The reason for failing to establish a patent airway with the size 3 LMA in the same patient in whom previous use had been successful is unclear. Reasons often cited for difficulty with LMA insertion and airway 
obstruction, apart from light anaesthesia and laryngospasm, lay in a failure to negotiate the back of the tongue, epiglottic downfolding and overinsertion or underinsertion. The size $21 / 2$ LMA itself is shorter at $12.5 \mathrm{~cm}$ versus $19 \mathrm{~cm}$ with an internal diameter of $8.4 \mathrm{~mm}$ versus $10 \mathrm{~mm}$. However, the likely reason was the size of the mask itself. It is credible that, in a morbidly obese female patient, the loss of upper airway tone, in combination with increased supraglottic folds of tissue, may result in a decreased space for the mask, thus causing potential folding of the size 3 tip onto itself and epiglottic downfolding. Alternatively, the underinsertion of the larger size 3 cuff may have in fact resulted in the LMA tip impinging on the arytenoids causing them to infold or for the tip itself to collide with the laryngeal inlet causing complete obstruction. The only major change on examination was the patient's weight gain with potential changes in the supraglottic tissues which may have been more suited to the smaller mask size of the size $2 \frac{1}{2} 2$ LMA. However, on searching the literature, there are no data looking at pharyngeal architecture in patients with increased BMIs and how this impinges on LMA size. Indeed, the manufacturers advocate a size 6 LMA for patients over $100 \mathrm{~kg}$ and a size $21 / 2$ for patients of $20-30 \mathrm{~kg}$. With the increased numbers of morbidly obese patients presenting for surgery and documented difficulty with mask ventilation, this is an area requiring further study.

Owing to the previous difficulties, an appropriate plan for this patient would have been to perform an awake FOI. It is unclear from the records as to why the procedure was not previously tolerated by the patient but highlights the importance of appropriate sedation, good topicalization, and skilled endoscopy. A number of different sedation techniques and drugs are used individually or in combination. The merits of propofol versus remifentanil have been previously discussed [1]. Although propofol has the benefit of amnesia, particularly of importance in patients requiring repeated procedures, remifentanil has been shown to generate better intubating conditions, is more 'forgiving' of inadequate topicalization, and advocates argue that amnesia is less of an issue if the procedure is done well with no patient distress. The learning curve for nasal FOI has been quoted as 18 to achieve intubation in less than $60 \mathrm{~s}$, but the number required to maintain those skills is unclear [2]. Indeed, awake FOI failure rates have been previously quoted as $1.5 \%$, and anaesthetists in the UK in comparison with other countries do not perform many awake FOIs, resulting in a rarely practised skill which is then used in difficult patients [3].

The merits of an inhalational versus intravenous induction to maintain spontaneous ventilation have been previously discussed in the literature, and the targetcontrolled infusion (TCI) of propofol may have given more control and perhaps averted the CICV scenario. However, it is likely that problems with upper airway obstruction would still have remained an issue in trying to achieve a deep enough plane of anaesthesia for airway manipulation even in the presence of airway topicalization. In addition, difficulties lay in deciding the appropriate weight for TCI pump programming.

Case reports of intubation using an AIC loaded on a fibreoptic scope and using a classic LMA in difficult intubations have been reported in the literature $[4,5]$. Indeed, there are two case series published regarding the use of the AIC via the classic LMA in adults, but none using a paediatric-sized LMA in this group [6,7]. This is the first case in the literature.

Finally, this case highlights several ethical issues and the importance of communication between the anaesthetist and the patient after the difficult situation of a previously failed awake FOI and the importance of informed consent.

We have described the successful rescue of a morbidly obese patient in a CICV scenario using a recognized technique yet in an unconventional way by using a paediatric-sized LMA in a morbidly obese adult. This case reiterates the difficulty of mask ventilation, a need for alternative techniques for airway patency, and further work required to ascertain the appropriate size of LMA in this group of patients when difficulty arises.

\section{References}

1 Rai M, Parry T, Dombrovskis A, et al. Remifentanil target-controlled infusion vs propofol target-controlled infusion for conscious sedation for awake fibreoptic intubation: a double-blinded randomized controlled trial. $\mathrm{Br} J$ Anaesth 2008; 100:125-130.

2 Smith J, Jackson A, Hurdley J, et al. Learning curves for fibreoptic nasotracheal intubation when using the endoscopic video camera. Anaesthesia 1997; 52:101-106.

3 Heidegger T, Gerig H, Ulrich B, et al. Structure and process quality illustrated by fibreoptic intubation: analysis of 1612 cases. Anaesthesia 2003; 58:734-739.

4 Zura A, Doyle D, Orlandi M. Use of the Aintree intubation catheter in a patient with an unexpected difficult airway. Can J Anesth 2005; 52:646-649.

5 Avitsian R, Doyle D, Helfand R, et al. Sucessful reintubation after cervical spine exposure using an Aintree intubation catheter and a laryngeal mask airway. J Clin Anesth 2006; 18:224-225.

6 Cook T, Seller C, Gupta K, et al. Nonconventional uses of the Aintree intubating catheter in management of the difficult airway. Anaesthesia 2007; 62:169-174.

7 Higgs A, Clark E, Premraj K. Low-skill fibreoptic intubation: use of the Aintree Catheter with the classic LMA. Anaesthesia 2005; 60:915-920.

DOI:10.1097/EJA.0b013e32832a2273

\section{Desaturation during Onyx embolization for intracranial arteriovenous malformations Irene Asouhidou ${ }^{a}$, Vasilios Katsaridis ${ }^{b}$ and George Georgiadis $^{a}$}

asecond Department of Anesthesiology and ${ }^{b}$ Unit for Endovascular Neurosurgery, Neurosurgical Department, 'G. Papanikolaou' Regional Hospital, Exohi, Thessaloniki, Greece 
Correspondence to Irene Asouhidou, MD, PhD, 15-17 Agiou Evgeniou Street, Kalamaria 55133, Thessaloniki, Greece

Tel: +30 2310452560; e-mail: iasouhidou@aol.com

Received 25 January 2009 Revised 4 March 2009 Accepted 19 March 2009

\section{Editor,}

Endovascular treatment of arteriovenous malformation (AVM) with the Onyx Liquid Embolic System (Onyx; Micro Therapeutics, Inc., Irvine, California, USA) can achieve a high occlusion rate, enhance the safety of the operation and improve the clinical prognosis for the patients compared with other embolic agents [1,2]. The Onyx Liquid Embolic System is a newer embolic agent that was developed in the early 1990s [1]. Onyx consists of ethylene vinyl alcohol dissolved in dimethyl sulphoxide (DMSO) and suspended micronized tantalum powder to provide contrast for visualization under fluoroscopy. In the present review, we report our experience with desaturation during embolization of AVMs.

Forty-six patients, 26 male and 20 female, $10-73$ years of age (mean age $38.4 \pm 16.75$ ), who were treated for AVMs by an endovascular approach using Onyx over a period of 10 months (January-October 2008) were enrolled in this study. General anaesthesia was induced with propofol $\left(2 \mathrm{mg} \mathrm{kg}^{-1}\right)$, fentanyl $\left(2 \mu \mathrm{g} \mathrm{kg}^{-1}\right)$ and cicatracurium $\left(0.15 \mathrm{mg} \mathrm{kg}^{-1}\right)$ and was maintained with continuous intravenous remifentanil and sevoflurane (minimum alveolar concentration $0.5-0.8)$ in $50 \% \mathrm{O}_{2}-\mathrm{N}_{2} \mathrm{O}$. Ventilation was maintained to achieve a $\mathrm{PaCO}_{2}$ of $30-35 \mathrm{mmHg}$. Heart rate $(\mathrm{HR})$, intraarterial blood pressure (IBP), oxygen saturation $\left(\mathrm{SpO}_{2}\right)$ and end-tidal $\mathrm{CO}_{2}\left(\mathrm{EtCO}_{2}\right)$ values were continuously monitored. $\mathrm{HR}$, IBP and $\mathrm{SpO}_{2}$ changes in response to DMSO and Onyx injection were recorded.

Seventeen of the patients developed desaturation during the infusion of DMSO; 11 of them demonstrated 3\% desaturation from baseline, and six had severe desaturation (4-8\% below baseline). None of these patients had any cardiological or pulmonary medical history. No significant changes in blood pressure (BP), HR or ECG were observed that could be attributable to DMSO infusion. The episodes of oxygen desaturation lasted a few minutes and the saturation returned to baseline, without any other clinical concerns during the procedure. Because of the fact that the desaturation was minimal, arterial blood gases were not taken. In only one case, in a patient with a giant AVM, we observed severe desaturation $\left(\mathrm{SpO}_{2} 89 \%\right)$ after recovery from anaesthesia, accompanied by tachypnoea. The first arterial blood gases revealed hypoxaemia ( $p \mathrm{O}_{2} 61.8 \mathrm{mmHg}$ ). $\mathrm{S} p \mathrm{O}_{2}$ gradually improved to $97 \%$, $p \mathrm{O}_{2}$ returned to normal $\left(\mathrm{O}_{2} 92.3 \mathrm{mmHg}\right)$ and the patient recovered fully $20 \mathrm{~min}$ later and was discharged from the postanaesthesia care unit. There were no other adverse events related to Onyx or anaesthesia. We saw no evidence of toxicity or any anaesthetic complications in our group of patients, our only clinical concern being a tendency to oxygen desaturation, lasting a few minutes with no clinical consequence.

The advantage of using Onyx is that it is a radio-opaque nonadhesive liquid embolic material easily injected through a microcatheter. It eliminates the risk of gluing the catheter to the vessel and therefore allows a longer injection time and a wider range of different injection rates. The disadvantage of Onyx is that it uses DMSO as a solvent. DMSO is a hydrogen-bound disrupter, a celldifferentiating agent and a hydroxyl radical scavenger and has been used as an anticancer and an analgesic agent [3]. If given in too high a volume or concentration, or if it is injected too fast, DMSO is potentially toxic to blood vessels and may lead to acute vessel damage, vasospasm, endothelial necrosis and severe inflammatory response in the arterial wall [3]. Dudeck et al. [4] report that DMSO induced the most pronounced vasospasm with the longest recovery period of all solvents investigated. The systemic side effects of DMSO vary from bronchospasm and pulmonary oedema to vasospasm and cardiac arrest $[3,5]$. Systemic toxicity, resulting in cardiac complications, has therefore been a major concern $[2,6]$.

Previous studies had focused on comparing the effects of different solvents on BP, HR and ECG without, however, commenting on Onyx injection and $\mathrm{SpO}_{2}$ [4]. Pamuk et al. [7] demonstrated oxygen desaturation in the postoperative period for patients undergoing embolization of aneurysms using a combination of Onyx and stainlesssteel stents. In the embolization of AVMs, not only is the percentage of DMSO higher than that used for aneurysms but also larger volumes are given with repeated injections of DMSO; this may result in a potentially higher risk of complications.

In our case series, desaturation was an event with more than one possible explanation. It can be attributed to a reduction in vital lung capacity after injection of DMSO. For instance, the patient with severe desaturation was unable to achieve maximal expiration and increase the inspiratory volume capacity over the tidal volume (resting) when she was prompted to do so. There was no evidence of atelectasia due to anaesthetic agents, so one can hypothesize that the vital capacity was affected by the injection of DMSO. Prospective studies on pulmonary function in these cases should help clarify the mechanism of hypoxaemia.

Although it is known that most of the DMSO metabolites are eliminated through the kidneys, some of the early elimination occurs via the skin and lungs. Dilution of oxygen in the lungs may cause a relative decrease in the partial pressure of oxygen in the alveoli. Desaturation cannot be attributed to the use of dyes such as methylene 
blue and indocyanine green as these agents are not routinely used during embolizations.

The patient with severe desaturation of $\mathrm{S}_{\mathrm{O}} \mathrm{O}_{2}$ after extubation did not experience any respiratory distress or hypotension, and the $\mathrm{PaO}_{2}-\mathrm{FiO}_{2}$ was more than 200, so the possibility of pulmonary oedema and acute respiratory distress syndrome could not be established. Intraoperative embolism by air or Onyx is unlikely because patients did not present with tachycardia, systemic hypotension or cardiac arrhythmia in the intraoperative and postoperative period, and, also, the $\mathrm{EtCO}_{2}$ did not change in any of the patients.

Therefore, a larger prospective randomized study is needed to confirm our observation and explain its cause. Such a study should also include a longer follow-up period of oxygen monitoring.

\section{References}

1 Katsaridis V, Papagiannaki C, Aimar E. Curative embolization of cerebral arteriovenous malformations (AVMs) with Onyx in 101 patients. Neuroradiology 2008; 50:589-597.

2 Lv X, Jiang C, Zhang J, et al. Complications related to percutaneous transarterial embolization of intracranial dural arteriovenous fistulas in 40 patients. AJNR Am J Neuroradiol 2009; 30:462-468.

3 Santos NC, Figueira-Coelho J, Martins-Silva J, Saldanha C. Multidisciplinary utilization of dimethyl sulfoxide: pharmacological, cellular, and molecular aspects. Biochem Pharmacol 2003; 65:1035-1041.

4 Dudeck O, Jordan O, Hoffmann KT, et al. Organic solvents as vehicles for precipitating liquid embolics: a comparative angiotoxicity study with superselective injections of swine rete mirabile. AJNR Am J Neuroradiol 2006; 27:1900-1906.

5 Murugesan C, Saravanan S, Rajkumar J, et al. Severe pulmonary oedema following therapeutic embolization with Onyx for cerebral arteriovenous malformation. Neuroradiology 2008; 50:439-442.

6 Laurent A, Mottu F, Chapot R, et al. Cardiovascular effects of selected watermiscible solvents for pharmaceutical injections and embolization materials: a comparative hemodynamic study using a sheep model. PDA J Pharm Sci Technol 2007; 61:64-74.

7 Pamuk AG, Saatci I, Cekirge HS, Aypar U. A contribution to the controversy over dimethyl sulfoxide toxicity: anesthesia monitoring results in patients treated with Onyx embolization for intracranial aneurysms. Neuroradiology 2005; 47:380-386.

DOI:10.1097/EJA.0b013e32832bfdaa

\section{A novel technique for learning to intubate with the lightwand}

David L. Saliba II, Scott A. Miller and John E. Reynolds

Department of Anesthesiology, Section on Neuroanesthesia, Wake Forest University School of Medicine, Winston-Salem, North Carolina, USA

Correspondence to David L. Saliba II, MD, Department of Anesthesiology, Wake Forest University School of Medicine, Medical Center Boulevard, Winston-Salem, NC 27157, USA

Tel: +1 336716 4498; fax: +1 336716 8190; e-mail: dsaliba@wfubmc.edu

Received 13 April 2009 Accepted 27 April 2009

Editor,

The use of the lightwand for endotracheal intubation has been demonstrated to be a useful technique, particularly after failed laryngoscopy [1]. It is included in the American Society of Anesthesiologists' difficult airway algorithm as well [2]. Moreover, Friedman et al. [3] noted that patients had less dysphagia, dysarthria and a lower severity of sore throat with lightwand intubation than with standard laryngoscopy.

With the traditional teaching for lightwand intubation, the clinician holds the wand similar to a pencil, stands directly behind the patient's head, inserts the device into the side of the mouth and sweeps the tip to the midline [4]. Our teaching varies considerably from this approach and allows all providers to safely and quickly perform lightwand intubations, regardless of their level of experience.

The key aspect of our approach involves having the clinician stand to the left of the patient's head instead of the traditional intubating position. This stance provides numerous advantages. First, it gives the clinician a better view of the anterior neck by placing one's eyes directly above the target - the glottis. Second, it improves the degree of jaw thrust the clinician is able to provide with the left hand (thereby lifting the epiglottis away from the vocal cords). Third, standing to the patient's left forces the intubating right arm into a more rigid, elbow-elevated position. With the elbow elevated, glottic entry is smoother because it allows the clinician to

Fig. 1

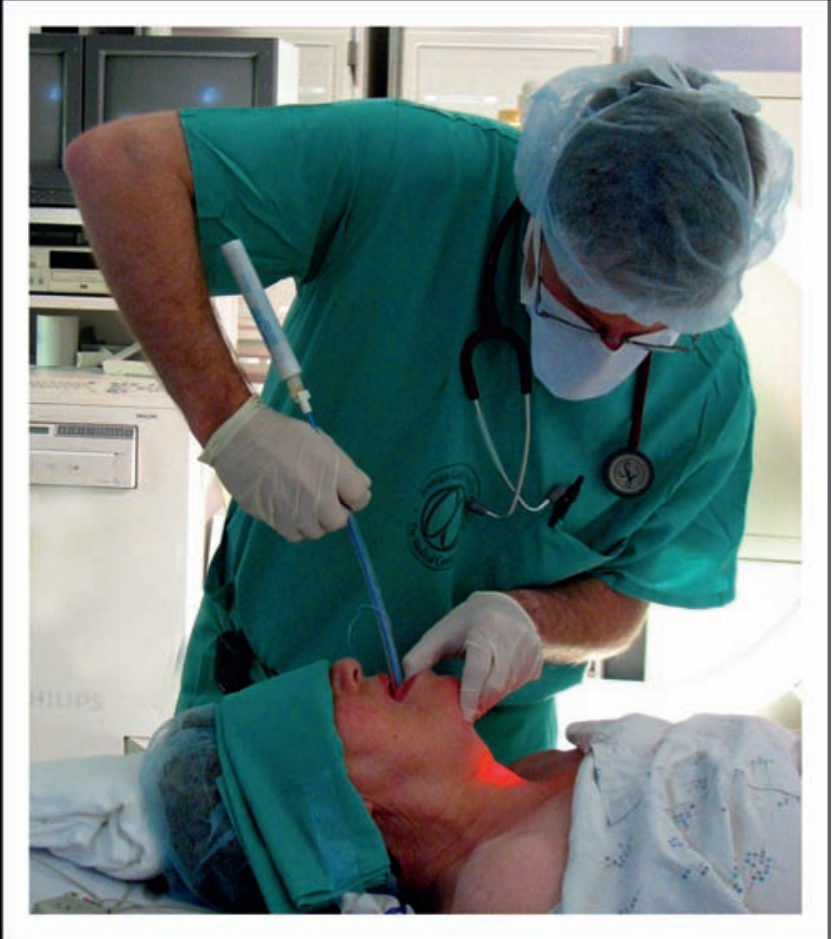

The Reynolds approach to lightwand intubation. 
gently pull the wand across the body in order to lift the light into the glottis (Fig. 1). Finally, this position allows the clinician to slide the endotracheal tube off the lightwand using the left hand because the right arm is now rigidly fixed upon entry through the glottis. This approach has greatly simplified every aspect of the procedure for us and has shortened its duration to a matter of seconds, regardless of the clinician's level of experience.

\section{References}

1 Weis FR, Hatton MN. Intubation by use of the light wand: experience in 253 patients. J Oral Maxillofac Surg 1989; 47:577-580.

2 American Society of Anesthesiologists Task Force on Management of the Difficult Airway. Practice guidelines for management of the difficult airway: an updated report by the American Society of Anesthesiologists Task Force on Management of the Difficult Airway. Anesthesiology 2003; 98:1269-1277.

3 Friedman PG, Rosenberg MK, Lebonbom-Mansour M. A comparison of light wand and suspension laryngoscopic intubation techniques in outpatients. Anesth Analg 1997; 85:578-582.

4 Davis L, Cook-Sather SD, aSchreiner MS. Lighted stylet tracheal intubation: a review. Anesth Analg 2000; 90:745-756.

DOI:10.1097/EJA.0b013e32832d780d 